\title{
Incidence and Risk Factors for Acute Kidney Injury in HIV Infection
}

\author{
Yongmei Li $^{\mathrm{a}}$ Michael G. Shlipak ${ }^{\mathrm{a}, \mathrm{b}} \quad$ Carl Grunfeld $^{\mathrm{a}}$ Andy I. Choi ${ }^{\mathrm{a}, \mathrm{b}}$ \\ ${ }^{a}$ Department of Medicine, San Francisco VA Medical Center, and ${ }^{b}$ Department of Epidemiology and Biostatistics, \\ University of California, San Francisco, San Francisco, Calif., USA
}

\section{Key Words}

Acute kidney injury · HIV • Chronic kidney disease •

Proteinuria $\cdot$ Hypoalbuminemia

\begin{abstract}
Background/Aims: Although HIV-infected persons are at higher risk for acute kidney injury (AKI) during hospitalization compared with their uninfected counterparts, risk factors for AKI are not well-defined. We aimed to describe the evolving incidence of AKI among HIV-infected individuals and to identify important AKI risk factors. Methods: We conducted a prospective cohort study of 56,823 HIV-infected persons in the Department of Veterans Affairs Clinical Case Registry. Outcomes were: AKI (acute in-hospital serum creatinine increase of $\geq 0.3 \mathrm{mg} / \mathrm{dl}$, or a relative increase by $50 \%$ or greater), and dialysis-requiring AKI. We used proportional hazards regressions to identify risk factors. Results: From its peak in 1995 at 62 per 1,000 person-years, the incidence of AKI declined after the introduction of highly active antiretroviral therapy (HAART) in 1996 to a low point of 25 per 1,000 person-years in 2006. Incidence of dialysis-requiring AKI declined in the early 1990s, but doubled between 2000 and 2006. Using multivariate proportional hazard regression, we identified the following strong risk factors for AKI: chronic kidney disease $\left(e G F R<60 \mathrm{ml} / \mathrm{min} / 1.73 \mathrm{~m}^{2}\right)(5.38,95 \% \mathrm{Cl}$ : 5.11-5.67), proteinuria (1.78, 1.70-1.87), low serum albumin $(<3.7 \mathrm{mg} / \mathrm{dl})(5.24,4.82-5.71)$, low body mass index $(<18.5$
\end{abstract}

$\left.\mathrm{kg} / \mathrm{m}^{2}\right)(1.69,1.54-1.86)$, cardiovascular disease $(1.77,1.66-$ $1.89)$, low CD4 count $\left(<200\right.$ cells $\left./ \mathrm{mm}^{3}\right)(2.54,2.33-2.77)$, and high viral load ( $\geq 100,000$ copies/ml) $(2.51,2.28-2.75)$. In addition, there was substantial heterogeneity in the strengths of risk factors for dialysis-requiring AKI before and after the introduction of HAART. Conclusions: Although AKI incidence has decreased during the HAART era, it remains common in HIV-infected persons and appears attributable to both kidney- and HIV-related factors.

Copyright $\odot 2012$ S. Karger AG, Basel

\section{Introduction}

Acute kidney injury (AKI), defined by a precipitous decline in glomerular filtration rate (GFR) [1], is associated with increased mortality, irreversible loss of kidney function [2, 3], increased length of hospital stay and excess health care costs [4]. HIV-infected persons are at higher risk for AKI compared to their uninfected counterparts [5]. We previously examined the long-term consequences of AKI in HIV-infected persons, and we found that the severity of AKI was independently associated with risk for heart failure, atherosclerotic cardiovascular events, end-stage renal disease (ESRD), and mortality

Dr. Andy Choi passed away on August 14th, 2010.

\section{KARGER}

Fax +4161306 1234

E-Mail karger@karger.ch

www.karger.com (c) 2012 S. Karger AG, Basel

0250-8095/12/0354-0327\$38.00/0

Accessible online at:

www.karger.com/ajn
Michael G. Shlipak, MD, MPH, Chief of General Internal Medicine

San Francisco Veterans Affairs Medical Center

4150 Clement Street, Box 111A1

San Francisco, CA 94121 (USA)

Tel. +1 415750 2093,E-Mail michael.shlipak@ucsf.edu 
among those who survived at least 3 months after discharge from their first hospitalization [2].

Although AKI appears to be a potent risk factor for adverse clinical outcomes in HIV-infected persons, the risk factors for AKI are not well-defined. Prior studies found that characteristics of advanced HIV-infection were the predominant risk factors for AKI during the highly active antiretroviral therapy (HAART) era [5-7] as in the pre-HAART era [8-10]. However, risk factors related to kidney disease were not fully evaluated, nor were they compared in strength with HIV-related factors. These prior studies were also limited by their inability to examine trends in AKI risk over time [6, 8-10], by the use of ICD 9-based definitions of AKI [5], and by a relatively small number of AKI events [6, 7].

In this study, we hypothesized that the risk factor profile of AKI may have changed in the late ART era, as HIV has become a more chronic disease $[11,12]$. Using the Department of Veterans Affairs HIV Clinical Case Registry (CCR) [13], we conducted this observational cohort study to describe the incidence of AKI and its risk factors, and to explore the evolution of this disease since the advent of HAART. We hypothesized that markers of kidney health and traditional risk factors for kidney disease would have increased in importance since the advent of HAART, whereas the significance of HIV-related risk factors would be decreased.

\section{Methods}

Data Sources and Study Population

We used the Department of Veterans Affairs HIV CCR as the primary data source. Details of data sources have been described previously [2]. We included all HIV-infected individuals in the CCR followed in the Veterans Health Administration between 1984 and 2007, with the exclusion of veterans with ESRD treated by chronic dialysis or kidney transplant. We also excluded individuals who had experienced AKI prior to the first known documentation of HIV. Patients entered this study on the date of their first known documentation of HIV and remained until their first episode of AKI, death, or their last date of follow-up (January 2007).

\section{Outcomes}

We defined AKI as any stage of AKI according to the Acute Kidney Injury Network (AKIN) criteria based on only in-hospital acute changes in the serum creatinine [14]. AKI stage I was categorized as a crude serum creatinine increase of $0.3 \mathrm{mg} / \mathrm{dl}$ or greater, or a relative increase between 50 and 100\%; stage II was categorized as a relative increase between 100 and $200 \%$; and stage III as either a relative increase greater than $200 \%$, or a crude increase of $0.5 \mathrm{mg} / \mathrm{dl}$ from the baseline among individuals with a serum creatinine level of $4.0 \mathrm{mg} / \mathrm{dl}$ or greater. Changes in creatinine level were defined as the difference between the peak serum creatinine level during hospitalization and the most recent measurement prior to hospitalization, or the nadir creatinine value measured during hospitalization if a recent outpatient serum creatinine level was not available.

In addition, we separately categorized individuals who experienced AKI that required dialysis treatment during their hospitalization, identified using validated diagnostic and procedural codes [15]. The primary outcome was time from first documentation of HIV to in-hospital AKI stage I or higher. The secondary outcome was time from first documentation of HIV to dialysisrequiring $\mathrm{AKI}$.

\section{Predictors of AKI}

We assessed markers of kidney health, traditional risk factors of kidney disease and HIV-related risk factors. Kidney status was measured as chronic kidney disease (CKD) based on low estimated glomerular filtration rate (eGFR) $\left(<60 \mathrm{ml} / \mathrm{min} / 1.73 \mathrm{~m}^{2}\right)$ and as the presence of proteinuria. eGFR was calculated using the abbreviated Modification of Diet in Renal Disease (MDRD) formula based on age, sex, race and serum creatinine. This equation was used clinically during this time period. Proteinuria was defined by urine dipstick measurements greater than $30 \mathrm{mg} / \mathrm{dl}$. We also included serum albumin categorized into quartiles $(<3.7,3.7-3.9$, $4.0-4.2$, and $\geq 4.3 \mathrm{mg} / \mathrm{dl})$ and body mass index $(<18.5,18.5-24.9$, $\geq 25$ ). Traditional risk factors for kidney disease included prevalent diabetes, hypertension, dyslipidemia and cardiovascular disease. HIV-related risk factors were CD4 count, viral load, and hepatitis $\mathrm{C}$ virus infection. We adjusted for other comorbid conditions that would influence either the likelihood of hospitalization or AKI: hepatitis B virus infection, liver disease, lung disease, and smoking, which were identified using laboratory results, physician problem lists, responses to VA-mandated provider queries, ambulatory and hospitalization discharge diagnosis, procedures, and medication prescriptions as described previously [2]. All the above characteristics were modeled as time-updated covariates, except for age, sex and race.

\section{Statistical Analysis}

We compared baseline characteristics between patients with and without incident AKI using t tests and chi-square tests. Then, we calculated incidence rates of AKI and dialysis-requiring AKI by calendar year to portray longitudinal trends. We allowed a patient to contribute a maximum of one AKI episode per calendar year between 1986 and 2006. Incidence of each AKI definition was presented as cases per 1,000 person-years.

To identify risk factors for AKI, we constructed multivariate Cox proportional hazards regressions, using Schoenfeld's tests to confirm the proportional-hazards assumption. We first tested individual factors in univariate Cox models. We then developed multivariate models and included all variables with $\mathrm{p}<0.05$ by a forward selection procedure. For the dialysis-requiring AKI outcome, we stratified by ART treatment era, due to some large differences we observed in the associations of risk factors between the two ART treatment eras. For the pre-HAART treatment period, we excluded viral load from the list of potential covariates because widespread availability of the technology to quantify viral load was limited prior to 1995 [16].

Data management and analyses were performed using STATA version 11.0 (StataCorp, College Station, Tex., USA). 
Fig. 1. Acute kidney injury rates (a), and dialysis-requiring acute kidney injury rates (b) between 1986 and 2006.

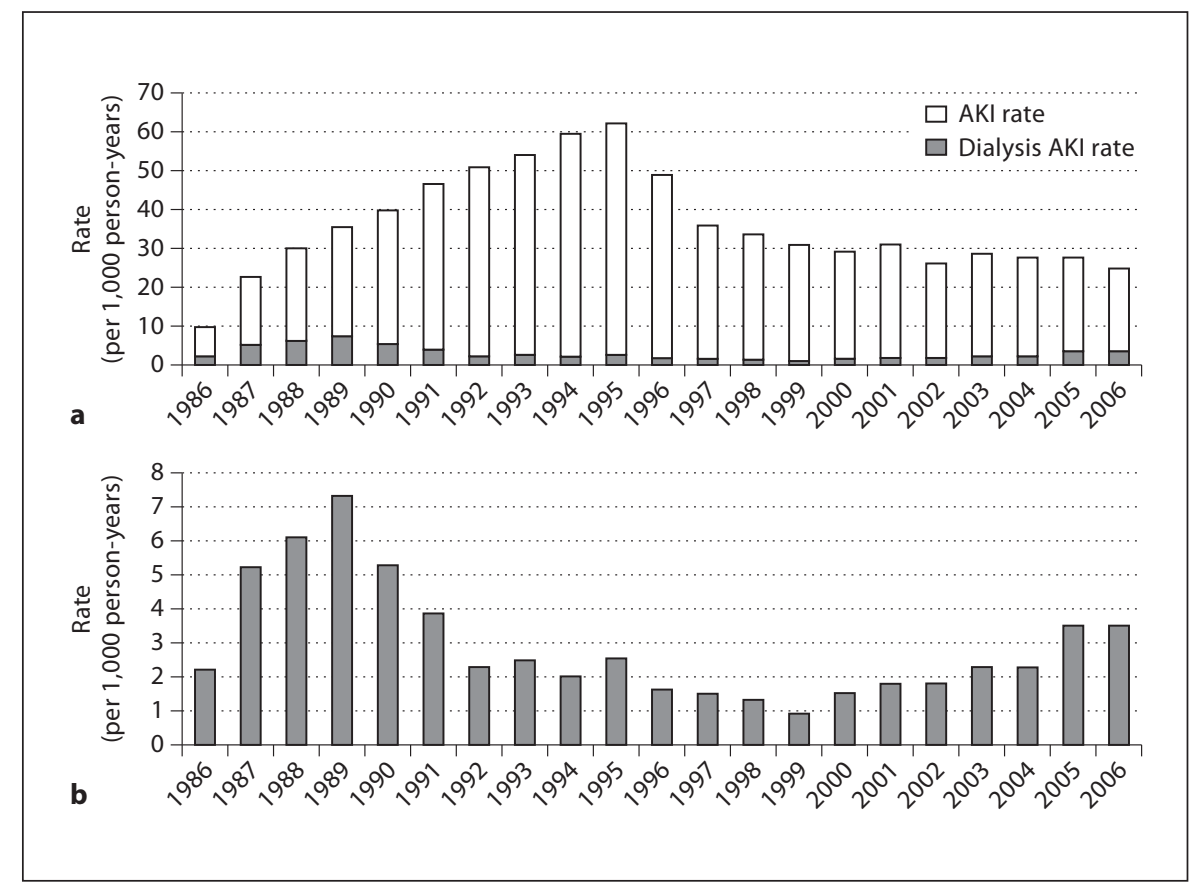

\section{Results}

We identified 59,913 HIV-infected patients with documented HIV infection followed in the VA healthcare system between January 1984 and January 2007. After excluding 491 patients who had ESRD and 2,599 patients who experienced AKI prior to the date of their first known documentation for HIV, there were 56,823 patients included in the analytic cohort. The median followup time was 5.1 years.

\section{Baseline Characteristics}

Among 8,477 patients who developed AKI, 6,948 had stage I (82.0\%), 363 stage II (4.3\%), 578 stage III (6.8\%) and 588 dialysis-requiring AKI (6.9\%). In comparisons of baseline characteristics, patients with subsequent AKI had a less favorable HIV-infection profile (lower CD4 count and higher viral load), were less likely to be overweight, and were more likely to be black, have diabetes mellitus and be infected with hepatitis $\mathrm{C}$ compared to persons without a future AKI episode (table 1). Those with AKI were not older, did not have more hypertension and fewer were smokers. With regard to kidney-related factors, the AKI group was approximately three times as likely as the non-AKI group to have baseline CKD, proteinuria, and low serum albumin.

\section{Incidence of AKI and Dialysis-Requiring AKI}

The year 1986 had the lowest AKI incidence rate of 10 per 1,000 person-years, followed by a gradual increase over a decade to a peak at 62 per 1,000 person-years in 1995 (fig. 1). Starting in 1996, AKI incidence declined consistently until 2006, decreasing overall by more than $50 \%$. The time trend in incidence of dialysis-requiring AKI differed from incident AKI as the rate peaked in 1989 at about 7.5 per 1,000 person-years and reached a nadir in 1999, but then has since risen steadily through the end of 2006.

\section{Risk Factors for AKI}

In stratified Cox proportional hazard regressions, the risk factors for overall AKI did not differ substantially in the pre-HAART and HAART eras, as the reduction was seen in all subgroups (data not shown). Therefore, a single model combining both periods was used (table 2). The risk for AKI was over 5-fold for patients with CKD (eGFR $<60 \mathrm{ml} / \mathrm{min} / 1.73 \mathrm{~m}^{2}$ ) compared with patients without $\mathrm{CKD}$, and proteinuria was associated with a near doubling of risk. Black race, hypertension, diabetes, cardiovascular disease, hepatitis $\mathrm{C}$ and low BMI also had significant, but weaker AKI risk associations. Notably, prior cardiovascular disease had a much stronger association with AKI than traditional risk factors such as hypertension and diabetes. Serum albumin level had a graded as- 
Table 1. Baseline characteristics of HIV-infected veterans with and without acute kidney injury (AKI) during follow-up

\begin{tabular}{|c|c|c|c|}
\hline & $\begin{array}{l}\text { No AKI } \\
(\mathrm{n}=48,346)\end{array}$ & $\begin{array}{l}\text { AKI } \\
(\mathrm{n}=8,477)\end{array}$ & $\begin{array}{l}\mathrm{p} \\
\text { value }\end{array}$ \\
\hline Age, years & $43.5(10.3)$ & $42.7(9.7)$ & $<0.001$ \\
\hline Female & 1.8 & 1.4 & 0.03 \\
\hline Race & & & $<0.001$ \\
\hline White & 27.2 & 20.0 & \\
\hline Black & 28.9 & 38.0 & \\
\hline Other & 43.9 & 42.0 & \\
\hline Body mass index* & & & $<0.001$ \\
\hline$<18.5$ & 3.8 & 8.0 & \\
\hline $18.5-24.9$ & 48.2 & 51.7 & \\
\hline$\geq 25.0$ & 47.9 & 40.3 & \\
\hline Hypertension & 13.3 & 11.8 & $<0.001$ \\
\hline Diabetes mellitus & 3.1 & 4.5 & $<0.001$ \\
\hline Dyslipidemia & 4.0 & 2.2 & $<0.001$ \\
\hline Liver disease & 1.1 & 1.3 & 0.059 \\
\hline Lung disease & 2.2 & 1.6 & 0.001 \\
\hline Smoking & 6.0 & 3.7 & $<0.001$ \\
\hline Cardiovascular disease & 3.0 & 2.9 & 0.651 \\
\hline Hepatitis $\mathrm{C}$ virus infection & 5.3 & 6.6 & $<0.001$ \\
\hline Hepatitis B virus infection & 1.5 & 1.6 & 0.281 \\
\hline CKD & 1.0 & 3.3 & $<0.001$ \\
\hline Proteinuria & 4.4 & 12.9 & $<0.001$ \\
\hline Serum albumin $<3.7 \mathrm{mg} / \mathrm{dl}$ & 5.3 & 14.6 & $<0.001$ \\
\hline Antiretroviral therapy** & 9.7 & 6.5 & $<0.001$ \\
\hline CD 4 count, cells $/ \mathrm{mm}^{3}$ & $305.5(335.9)$ & $243.9(295.2)$ & $<0.001$ \\
\hline Viral load, log copies/ml & $3.7(1.5)$ & $4.0(1.6)$ & $<0.001$ \\
\hline
\end{tabular}

Reported as proportion with condition (\%); continuous variables reported as mean (standard deviation). CKD defined as estimated glomerular filtration rate $<60 \mathrm{ml} / \mathrm{min} / 1.73 \mathrm{~m}^{2}$; proteinuria defined as $\geq 30 \mathrm{mg} / \mathrm{dl}$ on dipstick urinalysis. * Among those with BMI measured. ${ }^{* *}$ Percent of patients using antiretroviral therapy at baseline.

sociation with AKI risk across quartiles: compared with patients in the top quartile of serum albumin $(\geq 4.3 \mathrm{mg} /$ $\mathrm{dl})$, patients in the low quartile of serum albumin $(<3.7$ $\mathrm{mg} / \mathrm{dl}$ ) had a 5 -fold risk for AKI, while patients in the 2 nd and 3rd quartiles had moderately higher AKI risks. High viral load $(\geq 100,000$ copies $/ \mathrm{ml})$ and low CD4 count $\left(<200\right.$ cells $\left./ \mathrm{mm}^{3}\right)$ were also strong factors, with more than two-fold risks for AKI, while CD4 counts between $200-350$ cells $/ \mathrm{mm}^{3}$ were also associated with significantly elevated risk.

\section{Risk Factors for Dialysis-Requiring AKI}

Because of substantial heterogeneity in risk associations, risks for dialysis-requiring AKI were assessed sep-
Table 2. Risk Factors for acute kidney injury among HIV-infected veterans

\begin{tabular}{|c|c|c|}
\hline Characteristic & $\begin{array}{l}\text { Hazard ratio } \\
(95 \% \mathrm{CI})\end{array}$ & $\begin{array}{l}\mathrm{p} \\
\text { value }\end{array}$ \\
\hline \multicolumn{3}{|l|}{ Age, years } \\
\hline$<35$ (lowest quartile) & Reference & - \\
\hline $35-40$ & $1.03(0.96-1.09)$ & 0.448 \\
\hline $41-47$ & $1.02(0.96-1.09)$ & 0.499 \\
\hline$\geq 48$ (highest quartile) & $0.96(0.89-1.02)$ & 0.174 \\
\hline \multicolumn{3}{|l|}{ Race } \\
\hline White & Reference & - \\
\hline Black & $1.22(1.14-1.29)$ & $<0.001$ \\
\hline Hypertension & $1.08(1.02-1.15)$ & 0.014 \\
\hline Diabetes & $1.22(1.13-1.31)$ & $<0.001$ \\
\hline Dyslipidemia & $0.88(0.81-0.95)$ & 0.001 \\
\hline Cardiovascular disease & $1.77(1.66-1.89)$ & $<0.001$ \\
\hline Hepatitis $C$ virus & $1.33(1.26-1.40)$ & $<0.001$ \\
\hline \multicolumn{3}{|l|}{ CD 4 count, cells $/ \mathrm{mm}^{3}$} \\
\hline$>500$ & Reference & - \\
\hline $350-499$ & $1.09(0.97-1.22)$ & 0.135 \\
\hline $200-350$ & $1.29(1.16-1.42)$ & $<0.001$ \\
\hline $0-199$ & $2.54(2.33-2.77)$ & $<0.001$ \\
\hline \multicolumn{3}{|l|}{ Viral load, copies/ml } \\
\hline $0-499$ & Reference & - \\
\hline 500-29,999 & $1.09(0.99-1.18)$ & 0.077 \\
\hline $30,000-100,000$ & $1.55(1.40-1.72)$ & $<0.001$ \\
\hline$\geq 100,000$ & $2.51(2.28-2.75)$ & $<0.001$ \\
\hline \multicolumn{3}{|l|}{ Body mass index } \\
\hline$<18.5$ & $1.69(1.54-1.86)$ & $<0.001$ \\
\hline $18.5-25.0$ & Reference & - \\
\hline$\geq 25.0$ & $0.82(0.77-0.88)$ & $<0.001$ \\
\hline \multicolumn{3}{|l|}{ Albumin, mg/dl } \\
\hline$\geq 4.3$ (highest quartile) & Reference & - \\
\hline $4.0-4.3$ & $1.30(1.17-1.44)$ & $<0.001$ \\
\hline $3.7-4.0$ & $1.75(1.59-1.94)$ & $<0.001$ \\
\hline$<3.7$ (lowest quartile) & $5.24(4.82-5.71)$ & $<0.001$ \\
\hline $\mathrm{eGFR}<60 \mathrm{ml} / \mathrm{min} / 1.73 \mathrm{~m}^{2}$ & $5.38(5.11-5.67)$ & $<0.001$ \\
\hline Proteinuria & $1.78(1.70-1.87)$ & $<0.001$ \\
\hline
\end{tabular}

Multivariate model includes factors with a $\mathrm{p}$ value $<0.05$ in univariate analysis. All factors in table 1 were evaluated as candidate predictors. All estimates are adjusted for receipt of antiretroviral therapy.

arately for pre-HAART and HAART eras (table 3). Age was not an independent risk factor, but black race was strongly associated with dialysis-requiring AKI, especially in the pre-HAART era. As hypothesized, the importance of hypertension and cardiovascular disease as risk factors increased in the HAART era; in contrast, the risk associated with diabetes decreased. CKD and proteinuria had consistently strong associations with dialysis-requiring AKI across both treatment eras. 
Table 3. Risk factors for dialysis-requiring acute kidney injury among HIV-infected veterans, stratified by antiretroviral treatment era

\begin{tabular}{|c|c|c|c|c|}
\hline \multirow[t]{2}{*}{ Characteristic } & \multicolumn{2}{|l|}{ 1986-1995 } & \multicolumn{2}{|l|}{ 1996-2006 } \\
\hline & HR (95\% CI) & $\mathrm{p}$ value & HR (95\% CI) & $\mathrm{p}$ value \\
\hline \multicolumn{5}{|l|}{ Age, years } \\
\hline$<35$ (lowest quartile) & Reference & - & Reference & - \\
\hline $35-40$ & $1.28(0.91-1.81)$ & 0.160 & $1.43(0.98-2.10)$ & 0.067 \\
\hline $41-47$ & $1.07(0.73-1.56)$ & 0.742 & $1.39(0.96-2.02)$ & 0.082 \\
\hline$\geq 48$ (highest quartile) & $0.76(0.49-1.16)$ & 0.204 & $1.40(0.97-2.02)$ & 0.071 \\
\hline \multicolumn{5}{|l|}{ Race } \\
\hline White & Reference & - & Reference & - \\
\hline Black & $4.89(2.08-11.48)$ & $<0.001$ & $1.69(1.31-2.18)$ & $<0.001$ \\
\hline Hypertension & - & - & $1.85(1.44-2.36)$ & $<0.001$ \\
\hline Diabetes & $3.60(2.30-5.63)$ & $<0.001$ & $1.38(1.06-1.80)$ & 0.015 \\
\hline Cardiovascular disease & $1.53(0.80-2.94)$ & 0.197 & $1.93(1.52-2.45)$ & $<0.001$ \\
\hline Hepatitis $\mathrm{C}$ virus & $2.87(1.66-4.96)$ & $<0.001$ & $1.37(1.09-1.72)$ & 0.007 \\
\hline \multicolumn{5}{|l|}{ CD 4 count, cells $/ \mathrm{mm}^{3}$} \\
\hline$>500$ & Reference & - & Reference & - \\
\hline $350-499$ & $5.40(1.16-25.03)$ & 0.031 & $0.96(0.56-1.66)$ & 0.890 \\
\hline $200-350$ & $4.44(0.97-20.34)$ & 0.055 & $1.93(1.23-3.00)$ & 0.004 \\
\hline $0-199$ & $7.12(1.73-29.36)$ & 0.007 & $4.21(2.85-6.20)$ & $<0.001$ \\
\hline \multicolumn{5}{|l|}{ Viral load, copies/ml } \\
\hline $0-499$ & Reference & - & Reference & - \\
\hline $500-29,999$ & - & - & $1.09(0.80-1.49)$ & 0.569 \\
\hline $30,000-100,000$ & - & - & $1.23(0.83-1.82)$ & 0.305 \\
\hline$\geq 100,000$ & - & - & $2.22(1.57-3.15)$ & $<0.001$ \\
\hline \multicolumn{5}{|l|}{ Body mass index } \\
\hline$<18.5$ & $1.30(0.27-6.14)$ & 0.743 & $1.21(0.79-1.85)$ & 0.375 \\
\hline $18.5-25.0$ & Reference & - & Reference & - \\
\hline$\geq 25.0$ & $2.07(0.75-5.72)$ & 0.163 & $0.73(0.57-0.94)$ & 0.013 \\
\hline \multicolumn{5}{|l|}{ Albumin, mg/dl } \\
\hline$\geq 4.3$ (highest quartile) & Reference & - & Reference & - \\
\hline $4.0-4.3$ & $0.63(0.10-3.76)$ & 0.609 & $3.74(1.05-13.25)$ & 0.041 \\
\hline $3.7-4.0$ & $1.71(0.42-6.86)$ & 0.451 & $4.44(1.29-15.26)$ & 0.018 \\
\hline$<3.7$ (lowest quartile) & $5.50(1.67-18.07)$ & 0.005 & $15.68(4.95-49.71)$ & $<0.001$ \\
\hline $\mathrm{eGFR}<60 \mathrm{ml} / \mathrm{min} / 1.73 \mathrm{~m}^{2}$ & $15.12(8.56-26.73)$ & $<0.001$ & $18.87(13.07-27.22)$ & $<0.001$ \\
\hline Proteinuria & $5.25(2.60-10.62)$ & $<0.001$ & $4.16(2.59-6.69)$ & $<0.001$ \\
\hline
\end{tabular}

Multivariate model includes factors with a $\mathrm{p}$ value $<0.05$ in univariate analysis. All factors in table 1 were evaluated as candidate predictors. All estimates are adjusted for receipt of antiretroviral therapy.

CD4 counts below 500 cells $/ \mathrm{mm}^{3}$ were strong risk factors in the pre-HAART era, but the hazard ratio for intermediate values weakened in the newer era, with CD4 counts $<200$ cells $/ \mathrm{mm}^{3}$ remaining as a strong risk factor and the range of $200-350$ cells $/ \mathrm{mm}^{3}$ still a significant risk factor. Hepatitis $\mathrm{C}$ also weakened, whereas serum albumin was stronger in the HAART era. High HIV viral load was a risk factor in the later era but was not readily available in the earlier era. Thus, several HIV-related factors remained associated, but the strength of association weakened in the newer treatment era.

\section{Discussion}

The overall incidence of in-hospital AKI has decreased with the advent of ART and stabilized ever since, whereas dialysis-requiring AKI initially declined in incidence until 1999, and then has risen steadily until the end of 2006. Overall, risk factors for AKI were led by markers of kidney health and serum albumin, followed by HIV-related factors, whereas traditional risk factors for kidney disease were far less important for AKI. For dialysis-requiring AKI, the risk factors were similar to that of the less severe 
AKI; however, several risk factors for dialysis-requiring AKI changed in importance from the early to late ART treatment era. Some well-known risk factors for kidney disease - black race, diabetes, and hepatitis - had stronger associations in the pre-HAART era. In contrast, the associations of CVD and hypoalbuminemia increased in the HAART treatment era, and the association of proteinuria with AKI remained constant. HIV-related factors (low CD4 count and viral load) remained strongly associated with AKI risk after the introduction of HAART. Of interest, the association of CD4 count, particularly between 200 and 499 cells $/ \mathrm{mm}^{3}$, weakened, although the range of 200350 cells $/ \mathrm{mm}^{3}$ remained significantly associated with AKI risk. These findings indicate that $\mathrm{AKI}$ remains common in HIV-infected persons, its risk factors are multifactorial in nature, and AKI may continue to evolve in incidence and risk factors with changing clinical practice.

Our results should be interpreted in the context of current literature that highlights the importance of immunodeficiency as a predominant risk factor for AKI in both pre-HAART and HAART eras. Wyatt et al. [5] compared incidence, predictors and outcomes of AKI in acute care hospitals in the years 1995 and 2003. They found that HIVinfected patients had an increased incidence of AKI in both early and late ART eras, and AKI was associated with older age, diabetes, liver disease, hepatitis co-infection and preexisting CKD. Similarly, in a retrospective analysis of HIV-infected patients recruited from a university-based hospital between 1998 and 2005, Roe et al. [7] found that AKI was associated with low CD4 count (<100 vs. $>200$ cells $/ \mathrm{mm}^{3}$ ), opportunistic and non-opportunistic infections, hepatitis $\mathrm{C}$ virus co-infection, and liver disease. In the same cohort study about HIV-infected patients attending an HIV center in London between 1999 and 2008, Ibrahim et al. [17] found that lower levels of CD4 ( $<200 \mathrm{vs.}$ $>350$ cells $/ \mathrm{mm}^{3}$ ) were strongly associated with higher AKI risk. In an observational study of HIV-infected patients followed in the ambulatory setting between 2000 and 2002, Franceschini et al. [6] found that advanced immunodeficiency ( $<200$ vs. $>200$ cells $\left./ \mathrm{mm}^{3}\right)$ and hepatitis C virus infection were associated with AKI. Subsequently those authors reported that the effect of low CD4 count was independent of hepatitis C infection [18]. It is evident that despite effective antiretroviral therapies, immunodeficiency continues to be a potent risk factor for AKI.

In contrast with the prominence of HIV-related factors, the importance of certain non-HIV related characteristics have diminished as risk factors for AKI. This might be attributable to the HIVMA-IDSA guidelines and European AIDS Clinical Society Guidelines [19] em- phasizing aggressive management of non-HIV-associated factors in both HIV and CKD care [20]. Prior studies have reported that in the HAART era, hypertension and diabetes were not independently associated with AKI in ambulatory patients $[6,7]$. However, for our analysis of dialysis-requiring AKI endpoints, we found that although diabetes decreased in strength as a risk factor between the two ART treatment eras, it remained an independent risk factor along with hypertension and cardiovascular disease.

In terms of incidence of AKI, direct comparisons across studies are difficult due to a lack of a consistent definition of AKI and inclusion criteria [5-7, 21]. However, our findings conform to previous results that the incidence of AKI has not decreased further in the HAART era. This finding might indicate possible increasing severity of underlying CKD, and may also reflect the lowered threshold for dialysis in the general population [21]. Increased use of dialysis to treat AKI in HIV-infected persons is supported by growing evidence of improved survival of HIV-infected persons with ESRD, which is now similar to that of HIV-negative persons, with a 1-year survival rate of $74 \%$ in HIV-infected patients who started dialysis in the years 1999 to 2000 [22].

Regarding markers of kidney health, our findings were consistent with previous results demonstrating their strength as markers of increased risk of AKI [17, 23, 24]. In an HIV cohort study, Ibrahim et al. [17] identified a 27-fold relative risk for AKI in patients with CKD compared with those with eGFR $>90 \mathrm{ml} / \mathrm{min} / 1.73 \mathrm{~m}^{2}$. In a large integrated healthcare system, Hsu et al. [23] found a two-fold odds ratio for dialysis-requiring AKI for eGFR between 45 and $60 \mathrm{ml} / \mathrm{min} / 1.73 \mathrm{~m}^{2}$ compared with eGFR $\geq 60 \mathrm{ml} / \mathrm{min} / 1.73 \mathrm{~m}^{2}$, and 2 to 3 times greater risk in patients with proteinuria compared with those without proteinuria. In a population-based cohort, Grams et al. [24] found a graded association of urine albumin-to-creatinine ratio (UACR) with AKI independent of eGFR, with relative risks of AKI ranging from 1.9 to 4.8 with far higher levels of UACR.

To our knowledge, this study is the first to demonstrate a graded association of lower serum albumin levels with AKI. Serum albumin is an index of visceral protein stores [25], a marker of nutrition status [26], a result of nephrotic syndrome and is affected by inflammation and acute infection. In a prospective cohort study, the Women's Interagency HIV Study, Feldman et al. [27] found that baseline serum albumin was an independent predictor of 3-year survival in HIV-infected women. The excess mortality risk associated with low serum albumin 
remained when patients with moderate to severe immunosuppression and abnormal kidney and liver function were excluded. The authors suggested that serum albumin may be an additional marker of HIV disease progression. Serum albumin is also an inflammatory biomarker that showed an inverse association with kidney function decline in the elderly [28]. Keller et al. [28] studied longitudinal kidney function decline in 4,128 subjects from the Cardiovascular Health Study and identified 1,059 subjects $(26 \%)$ with a rapid kidney function decline, defined as an annual loss of eGFR (cysC) $>3 \mathrm{ml} /$ $\min / 1.73 \mathrm{~m}^{2}$. They found that out of 10 inflammatory biomarkers, lower serum albumin was the only factor that was consistently associated with a rapid decline in kidney function. Our finding thus adds to the evidence that serum albumin might provide important prognostic information for HIV disease progression and kidney function decline.

The strengths and originalities of this study include the longitudinal nature of assessments in a large representative national database. We assessed a large number of subjects over an extended time period that supported our examination of time trends across antiretroviral treatment eras. Furthermore, we were able to assess AKI and severe AKI separately. In addition, we included all HIV-infected persons and investigated both outpatient and inpatient characteristics in a time-updated manner, and as a result, we were able to capture more novel risk factors of AKI. Finally, no other study to our knowledge has considered low serum albumin and being underweight as risk factors for AKI.

This study should also be interpreted in the context of its limitations. The majority of the subjects were male, and the mean baseline age was younger than in non-HIV studies. Urine dipstick was the only measurement available, and the proteinuria classification was binary. In addition, we did not evaluate the AKI risk associated with individual antiretroviral drugs, as that was beyond the scope of this study. Furthermore, less than one quarter of the participants had a pre-hospitalization measurement of serum creatinine, which may be a limitation of our results. Using the nadir in-hospital creatinine might have overestimated the incidence and severity of AKI, since the lowest baseline maximizes the relative increase. However, this would not affect the dialysis AKI endpoint. An additional limitation is that we do not have the admitting diagnosis for the hospitalizations complicated by AKI. The observed risk factors for AKI may partially reflect these conditions predisposing the patients to be hospitalized rather than direct renal effects.
In conclusion, this study underscores the importance of kidney status associated with AKI, and adds to the evidence that HIV disease progression is still a critical risk factor for AKI in the post-HAART era. Future study should evaluate whether similar risk factors are associated with progressive kidney disease in the ambulatory setting. While attending to chronic conditions such as hypertension, diabetes and cardiovascular disease, timely monitoring of disease severity using additional markers of health status, such as serum albumin and low BMI, could help to tailor AKI prevention strategies in HIVinfected persons.

\section{Acknowledgement}

This paper is dedicated to the memory of Andy I. Choi, MD and his dedication to the effects of kidney disease in HIV infection.

\section{Funding Sources}

This study was supported by grants from the National Institutes of Health (K23DK080645-01A1, K23AI65244, R01 DK066488-01, 1R03AG034871-01). These funding sources had no involvement in the design or execution of this study.

\section{Disclosure Statement}

The authors declare no potential conflicts of interest.

References

$$
\begin{aligned}
& \text { Lameire N, Van Biesen W, Vanholder R: The } \\
& \text { changing epidemiology of acute renal fail- } \\
& \text { ure. Nat Clin Pract Nephrol 2006;2:364- } \\
& 377 \text {. } \\
& \text { Choi AI, Li Y, Parikh C, Volberding PA, Sh- } \\
& \text { lipak MG: Long-term clinical consequences } \\
& \text { of acute kidney injury in the HIV-infected. } \\
& \text { Kidney Int 2010;78:478-485. } \\
& 3 \text { Hsu CY, Chertow GM, McCulloch CE, Fan } \\
& \text { D, Ordonez JD, Go AS: Nonrecovery of kid- } \\
& \text { ney function and death after acute on chron- } \\
& \text { ic renal failure. Clin J Am Soc Nephrol 2009; } \\
& 4: 891-898 \text {. } \\
& 4 \text { Lattanzio MR, Kopyt NP: Acute kidney in- } \\
& \text { jury: New concepts in definition, diagnosis, } \\
& \text { pathophysiology, and treatment. J Am Os- } \\
& \text { teopath Assoc 2009;109:13-19. } \\
& \text { Wyatt CM, Arons RR, Klotman PE, Klotman } \\
& \text { ME: Acute renal failure in hospitalized pa- } \\
& \text { tients with HIV: risk factors and impact on } \\
& \text { in-hospital mortality. AIDS 2006;20:561- } \\
& \text { 565. }
\end{aligned}
$$


-6 Franceschini N, Napravnik S, Eron JJ Jr, Szczech LA, Finn WF: Incidence and etiology of acute renal failure among ambulatory HIVinfected patients. Kidney Int 2005;67:15261531.

$>7$ Roe J, Campbell LJ, Ibrahim F, Hendry BM, Post FA: HIV care and the incidence of acute renal failure. Clin Infect Dis 2008;47:242249.

$\checkmark 8$ Rao TK, Friedman EA, Nicastri AD: The types of renal disease in the acquired immunodeficiency syndrome. N Engl J Med 1987; 316:1062-1068.

-9 Bourgoignie JJ, Meneses R, Ortiz C, Jaffe D, Pardo V: The clinical spectrum of renal disease associated with human immunodeficiency virus. Am J Kidney Dis 1988;12:131137.

$>10$ Valeri A, Neusy AJ: Acute and chronic renal disease in hospitalized AIDS patients. Clin Nephrol 1991;35:110-118.

$\checkmark 11$ Perazella MA: Acute renal failure in HIVinfected patients: a brief review of common causes. Am J Med Sci 2000;319:385-391.

12 Peraldi MN, Maslo C, Akposso K, Mougenot B, Rondeau E, Sraer JD: Acute renal failure in the course of HIV infection: a single-institution retrospective study of ninety-two patients and sixty renal biopsies. Nephrol Dial Transplant 1999; 14:1578-1585.

13 Backus L, Mole L, Chang S, Deyton L: The immunology case registry. J Clin Epidemiol 2001;54(suppl 1):S12-S15.

14 Mehta RL, Kellum JA, Shah SV, Molitoris BA, Ronco C, Warnock DG, Levin A: Acute kidney injury network: report of an initiative to improve outcomes in acute kidney injury. Crit Care 2007;11:R31.
15 Waikar SS, Wald R, Chertow GM, Curhan GC, Winkelmayer WC, Liangos O, Sosa MA, Jaber BL: Validity of international classification of diseases, ninth revision, clinical modification codes for acute renal failure. J Am Soc Nephrol 2006;17:1688-1694.

16 Pachl C, Todd JA, Kern DG, Sheridan PJ, Fong SJ, Stempien M, Hoo B, Besemer D, Yeghiazarian T, Irvine B, et al: Rapid and precise quantification of HIV-1 RNA in plasma using a branched DNA signal amplification assay. J Acquir Immune Defic Syndr Hum Retrovirol 1995;8:446-454.

Ibrahim F, Naftalin C, Cheserem E, Roe J, Campbell LJ, Bansi L, Hendry BM, Sabin C, Post FA: Immunodeficiency and renal impairment are risk factors for $\mathrm{HIV}$-associated acute renal failure. AIDS 2010;24:22392244.

18 Franceschini N, Napravnik S, Finn WF, Szczech LA, Eron JJ Jr: Immunosuppression, hepatitis $\mathrm{C}$ infection, and acute renal failure in HIV-infected patients. J Acquir Immune Defic Syndr 2006;42:368-372.

19 European AIDS Clinical Society (ed): Guidelines: Prevention and Management of NonInfectious Co-Morbidities in HIV. Copenhagen, European AIDS Clinical Society, 2011.

20 Gupta SK, Eustace JA, Winston JA, Boydstun II, Ahuja TS, Rodriguez RA, Tashima KT, Roland M, Franceschini N, Palella FJ, Lennox JL, Klotman PE, Nachman SA, Hall SD, Szczech LA: Guidelines for the management of chronic kidney disease in HIV-infected patients: recommendations of the HIV Medicine Association of the Infectious Diseases Society of America. Clin Infect Dis 2005;40: 1559-1585.
21 Hsu CY, McCulloch CE, Fan D, Ordonez JD, Chertow GM, Go AS: Community-based incidence of acute renal failure. Kidney Int 2007;72:208-212.

22 Ahuja TS, Grady J, Khan S: Changing trends in the survival of dialysis patients with human immunodeficiency virus in the United States. J Am Soc Nephrol 2002;13:18891893

23 Hsu CY, Ordonez JD, Chertow GM, Fan D, McCulloch CE, Go AS: The risk of acute renal failure in patients with chronic kidney disease. Kidney Int 2008;74:101-107.

24 Grams ME, Astor BC, Bash LD, Matsushita K, Wang Y, Coresh J: Albuminuria and estimated glomerular filtration rate independently associate with acute kidney injury. J Am Soc Nephrol 2010;21:1757-1764.

25 Ikizler TA, Wingard RL, Harvell J, Shyr Y, Hakim RM: Association of morbidity with markers of nutrition and inflammation in chronic hemodialysis patients: a prospective study. Kidney Int 1999;55:1945-1951.

26 Klein S: The myth of serum albumin as a measure of nutritional status. Gastroenterology 1990;99:1845-1846.

27 Feldman JG, Burns DN, Gange SJ, Bacchetti $\mathrm{P}$, Cohen M, Anastos K, Nowicki M, Delapena R, Miotti P: Serum albumin as a predictor of survival in HIV-infected women in the Women's Interagency HIV Study. AIDS 2000;14:863-870.

28 Keller C, Katz R, Sarnak MJ, Fried LF, Kestenbaum B, Cushman M, Shlipak MG: Inflammatory biomarkers and decline in kidney function in the elderly: the Cardiovascular Health Study. Nephrol Dial Transplant 2010; 25:119-124. 